\title{
Implications of Output Hypothesis in College English Translation Course
}

\author{
$\mathrm{Na} \mathrm{Hu}{ }^{1, a^{*}}$, Xing $\mathrm{Xu}^{2}$ \\ ${ }^{1}$ Humanity and Sociology Department ,Jingdezhen Ceramics Institute ,Jiangxi China \\ ${ }^{2}$ College of Information \& Engineering, Jingdezhen Ceramic Institute, Jiangxi, China \\ anala_whu@aliyun.com \\ * the corresponding author
}

Keywords: Output Hypothesis; Language Output; Translation Teaching; New Testing Models of CET4

\begin{abstract}
The significance of Swain's Output Hypothesis lies in the fact that the output of language is also an important cognitive tool, which helps the language learners to realize the problems during their language acquisition process and thus they are facilitated to use the target language more accurately. The low translation capacity is the most alarming problem for college English teaching and learning, which triggers the new translation testing models of CET4. This paper, aiming at improve the language teaching and learning in college English translation course, first introduces the basic claims and modeling strategies, and then tries to form at a better set-up for the translation course and its classroom activities driven by the Output Hypothesis.
\end{abstract}

\section{Introduction}

After realizing the same low speaking and writing capability of learners who have participated in the Canadian Immersion Course, Swain claimed the Output Hypothesis which claims that the understandable language input and output should both be included during the second language acquisition process. College English teaching is of the second language acquisition category, while the practical teaching process weighs more on language input rather than output. One case in point is that the college English translation course has long emphasized a lot on vocabulary and syntax while ignored the adequate practical translation practice. In her later research, she found that the language output activities such as speaking and writing are the dispensable part of second language acquisition. During their language teaching and research, the teachers also noticed that to cultivate the language learners' output competence is of the equal importance of input competence in college English teaching. Translation teaching is a significant component of college English teaching and an important measure to improve the students' output capacity, so to strengthen the translation capacity as a language output competence should be taken as the core of college English teaching.

\section{The current situation of college English translation teaching}

The uncertain teaching goal. The teaching goal for college is supposed to be: to cultivate the students' ability in reading, writing, listening, speaking and translating, thus they could communicate via English. Generally listening and reading are regarded as the input process, correspondingly, speaking and wring as the output process, and translating should be taken as the comprehensive ability of the former four abilities. In the actual teaching and learning process, both the teachers and learners have been aware of the significance of output activities in advancing the language learning process; however they still strayed away from the standards of "translating". In the broad sense, the translation competence doesn't only consist of one's translation skills but also one's cultural and professional skills [1]. Consequently, the teaching goal of college English translation teaching should be the training of translators with basic skills rather than the professional ones, and the translation teaching should weigh more on the cultivation of the learners' language and culture acquisition. 
The relatively outdated teaching methods. Firstly, the college English translation course still follows the teacher-oriented model, in which the reference book and the referential translation provided by the teachers are the only assessment standards for the translation practice in class, and this is the severe bound to the learners' enthusiasm and creativity. In addition, the class is still carried on the basis of "students interpret and then teachers comment" method, and the teachers' instructions are inclined to vocabulary and syntax without thinking about the participation of students. Consequently, the students do agree that they have enriched their vocabulary and grammar understructure, but they still feel lost in front of a concrete but similar translation task, not to mention the translation strategies they can apply. Anyhow, the majority of students hold a "not-knowing what to interpret and not-knowing how to interpret" attitude towards the translation process.

The new challenge from CET4. The proportion of translation has risen from $5 \%$ to $15 \%$, and correspondingly the testing model has been changed from the translation of 4 sentences to a whole paragraph. The scoring standards not longer remain on vocabulary and syntax, but turns to the students' basic translation skills and culture background. This new challenge calls for the learners' better language competence, especially their output competence. Therefore, the teaching goal and method should be improved on the basis of understandable input activities, and at the same the teaching efficiency should be advanced with the help of the "driven-by-output" model.

\section{The Output Hypothesis}

Translating and language output. Since 1985, the definition of output has consistently thriven to a new definition and the researchers together with learners have also conceived different understandings of this definition.

In 2000, Swain redefined "output" as the activities of "speaking, writing, collaborative dialogue, private speech, verbalizing, and languaging" [2]. In her early research stage, Swain simply referred to the product and outcome of language acquisition by using the term "output", while her later revised term spotlight the action and process of language learning. As to the significance of output activities in foreign language teaching and learning, most of the domestic researchers confined themselves to the speaking and writing activities and seldom set their foot in translating activities. However, based on the reform of college English teaching, Professor Wen stresses that "although listening and reading are basic and primary (in language acquisition), the outside world could not get to the actual contents of reading and listening without the externalized activities such as speaking, writing and translating" [3]. Hence, as one of the language output activities, translating is a higher embodiment of speaking and writing. Only when the college English teaching process lay equal stress on "translating" and "listening, speaking, reading and writing", could the translating competence as a language output activity be strengthened and the whole teaching quality of college English be improved.

The functions of language output. Why do the learners still take such a weak notice of language and its accurate expressions after considerable practice and testing? It is because of the lack of output activities that the learners could not come to realize the errors in their expression of a certain language. Swain summarized the three functions of output in 1995: 1) noticing/triggering function; 2) hypothesis testing function; 3) metalinguistic/reflective function [4]. The learning process of a foreign language is a process of "input $\rightarrow$ take-in $\rightarrow$ output", while the input part couldn't be automatically transformed into an output form. Only in the way of analyzing, in-taking together with practice and output, could a certain foreign language be mastered and internalized by the learners.

After the practice focused on vocabulary and syntax during the early stage of translation teaching, the learners' reading ability has been heightened and they also have mastered word-building and syntax to a certain degree. While the truth is their language still fails to express the meaning of the target translation assignment. Therefore, it's essential to strengthen the learners' practical translation ability and to enrich the amount and form of translation practice because they "have to use the language" [5]. Driven by the necessity of output activities, the learners certainly will realize the difference between 
what they've understood and what they could feedback afterwards, and consequently, they will be forced to NOTICE the right form of target language.

The current quality of language output. Comparing to the $15 \%$ examination ratio, the required instruction time of translation only takes less than $1 / 8$ of the total time although it's regarded as the most difficult part of CET. Regardless of the new challenge of the new translation testing model, teachers still pay the main attention to the basic practice of language drills such without noticing the practice of translation skills which are needed in bilingual transformation, which illustrates a qualitative difference does exist between college English translation teaching and "translation teaching activities" in the content of breadth and depth. In addition, one of the reform goals of college English teaching is to reduce the total teaching hours. To solve the qualitative problem of translation teaching caused by "lack of quantity", colleges and universities have to open elective courses associated with translation to seek the quantity and quality of language output activities for translation teaching based on ensuring the amount of time and task [6].

\section{The hypothesis output language activities}

In the traditional teaching of translation, the process of an ideal translation comes into exist in the following way: firstly the learners' trial run, then the teachers' instructions, the learners' analyzing and internalizing, and finally the retranslation of target assignment. However, in real teaching process, the target assignment has been simplified into two steps: the teachers' instruction and then the students' translation because of the "lack of quantity" mentioned above. This process goes through without the feedback from learners and teachers and it entirely neglects the fact that students are the agents in this whole process of teaching and learning. According to Swain's information-processing framework, the essence of the learners' translating/interpreting is kind of hypothesis/assumption of the target language. Teachers and learners should have a tentative translation and later verification together, to make the learners be aware of their problems in the aspect of in the form of language, translation skills and cultural knowledge.

The hypothesis of in-class output activities. Swain holds a view that a good in-class activity should be the one that advances the students' language output after discussion, for example, a writing assignment; and "any activities that have students talk, particularly when students reflect about their speaking or writing, are good activity" [7]. So is translation teaching, both the teachers and learners have to release themselves from the old in-class form, they have to talk, to use and to translate. By "talking-discovering-reflecting-and finally solving" problems in actual translation assignments, the learners could obtain their second language acquisition in a dynamic reflection. The verification of the translation assignment is also the implementation process, and the teachers could implement the whole class by constructing different classroom activities includes pair work' group discussion or professional translation work. If students talk together with classmates or their teachers, it's very often that they will have confidence in using their translation competence. Pair work or small group work may give learners more opportunities to use English and deepen their understanding of the target translation assignment. For example, in the group discussion, after the procedure of "trial translation first, discussion comes the next, problems emerge consequently and retranslation after reflection", learners will be keenly aware of the production process of target translation assignment and thus have a deepened understanding of the vocabulary ,grammar, cultural background and translation skills related to the target translation assignment. The whole teaching period for the translation course can be designed in Table 1.

The classification of output activities. In his ESA Theory, Harmer Jeremy puts forwards two kinds of output activities during the language learning process, as is shown in Table1. The first one is "practice output" [8], the one guided by the teacher in which the students spend most of time practicing pattern drills and sentence translation. This output is the typical output pattern of college English translation teaching, and it's an organized but restricted activity. The other is the communication 
output activity, driven by the need to finish a certain task; the learners have to communicate by using language as a tool, which brings about a higher level of creativity and the ability of autonomous learning.

One can't deny that one translation ability accumulates from the basic learning activities, let us say, the word-builds and pattern drills in the early stage, and then the text translation in the later stage. Therefore, the key teaching points should be different for each semester, for example, vocabulary and grammar should be the teaching focus for freshmen in the first year during which period the teachers should adapt the practice output activities in the class. And those activities revolve around the learners' "study", and the teaching model could be simplified into "ask-answer-and evaluate". When it comes to the learning phase in high grade, especially faced with the real challenge from CET4, the sophomores have to devote themselves in the text translation practice. To learn better, the students need to use the language first, so the "communication output" activities come into exist in this important period of translation teaching and learning. As for the "translation practice" part in the output procedure, teachers should keep in mind to "activate" the learners acquired basic translation knowledge from time to time, by taking the right classification of output activities, the college translation teaching could be appropriately achieved with the driver of output hypothesis.

Table 1 The design of translation teaching in different periods

\begin{tabular}{|l|l|l|l|l|}
\hline $\begin{array}{l}\text { Teaching } \\
\text { Period }\end{array}$ & Teaching Focus & Output Mode & In-class activities & Required Translation From \\
\hline $1^{\text {st }}$ term & $\begin{array}{l}\text { Vocabulary, } \\
\text { grammar, } \\
\text { sentence drills }\end{array}$ & practice & $\begin{array}{l}\text { Ask-answer-asses } \\
\mathrm{s}\end{array}$ & From English to Chinese \\
\hline $2^{\text {nd }}$ term & $\begin{array}{l}\text { Text translation } \\
\text { and basic } \\
\text { translation skills }\end{array}$ & communicative & $\begin{array}{l}\text { Discuss-translate- } \\
\text {-assess }\end{array}$ & From Chinese to English \\
\hline $3^{\text {rd }}$ term & $\begin{array}{l}\text { Reading, target } \\
\text { translation tasks }\end{array}$ & communicative & $\begin{array}{l}\text { Translation--discu } \\
\text { ssion--assessment } \\
\text {--retranslation }\end{array}$ & From Chinese to English \\
\hline
\end{tabular}

The assumption of future translation curriculum. At present, the translation exercises of the textbook and some of the sample practice of CET4 are the main teaching materials of college English translation teaching, and the output form of the learners' translation practice only remains in the written form [9]. Taking the new testing demands of CET, the translation course should be combined with other course to find a way out, for example, the combination of "reading course + translation course", in which the learners first get to know their flaws in language, cultural background knowledge and translation skills by the actual translation assignment, and then retry the target translation assignment by reading for the associated language and cultural information, and lastly obtain the internalized language acquisition by collaborative dialogue.

The teaching content can not only linger in the vocabulary and grammar level, the teaching connotation of language, such as the cognitive ability of language, the mode of thinking and cultural literacy, should be taken as the paramount concern of future translation curriculum. The "1+1" curriculum setting assumption not only strengthens the output drive in translation teaching which promotes the transfer from the particular emphasis on translation results to the proper stress on translation process, but also activates the cultivation of translation ability from the basic reading, speaking, listening and writing abilities.

The equal emphasis on input and output activities. Among all the research on language input and output in college English teaching, the domestic research mainly focuses on the comparison. From the aspect of input and output language theory, together with the comparison of Chinese and Western education mode, Wang (2003) presents his opinion of discussion and analysis of the reason why college English teaching always gets half the results with double the effort. He strong advocates that, 
first of all the traditional teaching mode should be reformed, in addition, to improve the efficiency of teaching the quantity and quality of in-class input and output activities should obtain equal emphasis [10].

The training of talents who have basic skills in translation needs to ensure the amount of language input, because quantitative change to a certain extent leads to the qualities change. The function of output in teaching should be highlighted, it's the same with translation teaching, and the translators have to devote themselves to the actual translation assignment and to experience the real language output process. Only in this way can they notice, inspect and feedback their language ability in translation. After the repeated the inspection and study, they will finally get to know "what to be translated, and how to translate".

\section{Conclusion}

The teaching of translation is one of the main teaching tasks for college English, and faced with the reality of the learners' poor translation ability and the new challenge from CET4, the teaching modes and methods call for improvement and advancement. During the teaching and research process, the essence of language teaching has progressed a lot, which not only places a high value on the learners' language acquisition ability but also lays much stress on the enhancement of the learners' cultural and translating abilities. Based on the need of communication or use, all those activities for example, writing, public speech and especially translation are driven by the learners' output ability which is beneficial to their comprehensive language ability. In all the translation classes drive by the output hypothesis, the three elements--- various in-class output activities, the classification of output activities in different learning phases together with the new curriculum set-up --- are the effective assessment of the learners' translation ability. By repeated self-inspection and self-assessment in the real translation output activities, the learners finally accomplish the acquisition of translation ability.

\section{Acknowledgments}

This research was financially supported by the Project of Jingdezhen City Social Science Research (2014-40, 2014-36, 2014-63).

\section{References}

[1] C. Nord: Text Analysis in Translation: Theory, Methodology, and Didactic Application of Model for Translation - Oriental Text Analysis (Foreign Language Teaching and Research Press, China 2006).

[2] S. Gass, C. Madden: Input in second language acquisition (Newbury House Publishers, USA, 1995) p. 235.

[3] Q. Wen: Foreign Language, (2008) No.2 ,p.2.

[4] Information on http://heep.unipus.cn/gykejianNews/files/23.pdf

[5] W. Wang: Journal of Hubei Polytechnic Institute, Vol. 14, (2011) No. 3, p. 62.

[6] Y. Shen: Exam Weekly, (2011) No. 60, p. 104.

[7] J. Gu: Overseas English, (2011) No. 8, p. 59.

[8] J. Harmer: The Practice of English Language Teaching (Longman, London 1983).

[9] Q. Wang: Foreign Language Education, Vol. 24, (2003) No. 3, p. 66.

[10] Z. Li : Journal of Liaocheng University (Social Science Edition) (2010) No. 2, p. 401. 